\title{
A autoetnografia como método criativo: experimentações com a esclerose múltipla
}

Autoethnography as a creative method: experimentations with multiple sclerosis

Fabiene Gama

\section{(2) OpenEdition}

Journals

Edição electrónica

URL: http://journals.openedition.org/aa/5872

DOI: $10.4000 /$ aa. 5872

ISSN: 2357-738X

Editora

Programa de Pós-Graduação em Antropologia Social (UnB)

\section{Edição impressa}

Paginação: 188-208

ISSN: 0102-4302

Refêrencia eletrónica

Fabiene Gama, «A autoetnografia como método criativo: experimentações com a esclerose múltipla», Anuário Antropológico [Online], v.45 n.2 | 2020, posto online no dia 28 maio 2020, consultado o 26 abril 2021. URL: http://journals.openedition.org/aa/5872 ; DOI: https://doi.org/10.4000/aa.5872

\section{(c) (i) (9)}

Anuário Antropológico is licensed under a Creative Commons Atribuição-Uso Não-Comercial-Proibição de realização de Obras Derivadas 4.0 International. 


\title{
A autoetnografia como método criativo: experimentações com a esclerose múltipla ${ }^{\S}$
}

\author{
Autoethnography as a creative method: experimentations with \\ multiple sclerosis \\ DOI: https://doi.org/10.4000/aa.5872
}

\begin{abstract}
Fabiene Gama • Universidade Federal do Rio Grande do Sul - Brasil
Professora do Departamento de Antropologia da Universidade Federal do Rio Grande do Sul. Coordenadora do Núcleo de Antropologia Visual (NAVISUAL/UFRGS) integrante do grupo de pesquisa "Corpos e decolonialidades em Saúde (CODEs/UNICAMP/CNPq), realiza pesquisas sobre gênero, saúde, autoetnografias, autorrepresentações, emoções e mobilizações políticas, utilizando a fotografia como ferramenta de pesquisa.
\end{abstract}

A esclerose múltipla é uma doença neurológica pouco conhecida. Crônica e sem cura, ela causa fraqueza, fadiga e uma ampla gama de sintomas motores, sensoriais e visuais. Descobri o que era esclerose múltipla e ser uma doente crônica ao ser diagnosticada com a doença em 2014 e passar a lidar com o cuidado médico. Essa aprendizagem ocorreu intelectual, mas também física e emocionalmente, pois apesar de desejar entender o que acontecia para tomar decisões sobre tratamentos, meus conhecimentos e desejos eram ignorados. Este artigo foca nessas experiências e nas implicações de ser uma paciente ativa. 0 que acontece quando paciente e médica discordam sobre o melhor tratamento? Como profissionais da saúde lidam com conhecimentos provenientes de outras áreas? Qual é o impacto das estruturas mediadoras da sociedade nas experiências de uma doença crônica? Para refletir sobre essas dinâmicas, passarei pelos diários que escrevi e pelas imagens fotos, raios-X, ressonâncias e imagens de laboratório - que produzi durante os primeiros tratamentos. Meu objetivo é examinar o impacto da equipe e dos aparatos médicos na experiência de uma doença crônica.
Multiple sclerosis is a little-known neurological disease. Chronic and with no cure, it causes weakness, fatigue and a wide range of motor, sensory, and visual symptoms. I found out what multiple sclerosis is and what is to be chronically ill when I was diagnosed with the disease in 2014 and started to deal with treatments. This learning took place intellectually, but also physically and emotionally. Despite of my intention to understand what was going on and make decisions about treatments, my knowledge and desires were ignored. This article focuses on those experiences and the implications of being an active patient. What happens when the patient and the doctor disagree about the best treatment? How do health professionals deal with knowledge from other areas? What is the impact of society's mediating structures on the experiences of a chronic disease? To reflect on these dynamics, I will go through the diaries I wrote and the images - photos, X-rays, resonances, and lab images - that I produced during the first treatments. My goal is to examine the impact of medical staff and devices on the experience of a chronic disease. 


\section{Introdução}

Este artigo trata da minha experiência com a esclerose múltipla, em especial sobre o que dela é experimentado socialmente. A partir dos debates antropológicos sobre percepção, sensorialidade e autoetnografia, analisarei aqui como os diversos encontros com pessoas (médicas, enfermeiras, técnicas, burocratas ${ }^{1}$ ), artefatos (seringas, máquinas, textos, imagens) e instituições (hospitais, SUS) me transformaram em uma doente crônica. E abordarei as implicações de ser uma paciente ativa. O que acontece quando paciente e médica discordam sobre o melhor tratamento a seguir? Como profissionais da área da saúde lidam com conhecimentos provenientes de outras áreas? Como uma experiência individual, a de uma doença crônica, é experimentada através das estruturas mediadoras da sociedade? Para ponderar sobre esse processo, passarei por trechos dos diários que escrevi e as imagens - fotos, raios-X, ressonâncias e imagens laboratoriais - que produzi durante os primeiros anos do diagnóstico. Meu objetivo é apresentar à leitora reflexões sobre o impacto de tais mediadores na experiência de uma doença crônica.

As imagens apresentadas neste artigo visam dialogar com as palavras, e não as ilustrar ou descrevê-las. Elas são fruto desta produção de conhecimento subjetivo e experimental que é a autoetnografia, a qual nega a separação entre racionalidades e emoções, dados e análises, Eu e o Outro. Elas apontam para expressões presentes no corpo (na pele e em outros órgãos) e/ou sobre ele, visando produzir um conhecimento que vai contra a "lógica iluminista, colonial e imperialista que desqualifica e reprime formas de conhecimento atreladas à experiência", como relatou Gustavo Raimondi (2019, p. 65-66). E trilha caminhos menos "seguros" que aqueles trilhados pelo conhecimento científico que se propõe neutro, objetivo. Ainda que isto ponha em risco o próprio conhecimento, visto que, como ressaltou Tânia Mara Campos de Almeida,

novos conceitos, matrizes interpretativas e procedimentos metodológicos nos diversos saberes acadêmicos têm sofrido resistência para se legitimarem como exegeses e epistemologias críticas do conhecimento instituído, para se firmarem contrapostas à divisão internacional do mercado intelectual mundial e à falsa ideia de neutralidade científica (Almeida, 2018, p. 212).

Gostaria, contudo, de chamar a atenção para algo da autoetnografia que gera problemas de interpretação em pessoas não habituadas a seu gênero literário: o que apresento aqui é fruto da minha experiência, mas do que dela também é partilhada com outras pessoas, como desenvolverei mais adiante. Assim, o que foi selecionado para ser exposto neste trabalho, assim como a forma como o que foi selecionado é apresentada, faz parte de todo um processo engajado com outras narrativas de pessoas com esclerose múltipla. E está relacionado, do começo ao fim, com a subversão desta forma normativa que, ao camuflar o acesso a subjetividades, impõe um padrão de produção de conhecimento bastante especifico, fruto do Iluminismo. Uma forma que tende "ao apagamento da presença do sujeito
$\S$ Uma primeira versão deste texto foi apresentada no 13 Women's Worlds Congress e 11 Seminário Internacional Fazendo Gênero, em 2017, em Florianópolis. Desde então, o texto vem sendo apresentado em palestras e congressos e contou com diversas contribuições, em especial da Prof ${ }^{a}$. Soraya Fleischer, do Departamento de Antropologia da UNB, a quem agradeço todo o incentivo para a publicação dele.

1 Neste texto usarei o sujeito indefinido e o plural sempre no feminino, com exceção de quando se tratar exclusivamente de homens. 
nos discursos produtores de conhecimento considerado 'formal', aquele que surge em espaços institucionalizados de saber, algo que remonta à separação entre os discursos científicos e não científicos” (Versiani, 2005, p. 19).

\section{Nota metodológica sobre a autoetnografia}

A autoetnografia escorrega, evita definições simplistas. É a colisão entre as ciências humanas e as artes, as teorias e as emoções, a "performatividade"- o que acontece agora - e a performance - o que já aconteceu (estudo feito) - é a presença do corpo do(a) pesquisador(a) na linha de frente da pesquisa, no momento da criação (texto ou a performance/apresentação) (Brilhante; Moreira, 2016, p. 1100).

Como dito, este trabalho foi desenvolvido através de uma metodologia que embora não seja nova, ainda é inovadora: a autoetnografia. De acordo com Ellis e Bochner (2000), a autoetnografia é um gênero autobiográfico de escrita e pesquisa que apresenta múltiplos níveis de consciência, conectando o pessoal ao cultural, expondo frequentemente um self vulnerável. Diferente da etnobiografia (Gonçalves; Marques; Cardoso, 2013) - na qual a antropóloga reflete sobre a trajetória de uma outra pessoa para analisar fenômenos socioculturais - na autoetnografia, a antropóloga reflete sobre sua própria experiência, ou a partir dela, para analisar questões da sociedade e/ou cultura à qual pertence.

Ela é uma metodologia que exige múltiplas camadas de reflexividade, uma vez que a pessoa que pesquisa e aquela que é pesquisada são a mesma. Para Grant (2014), pesquisas autoetnográficas desempenham um valioso papel na antropologia: expõem partes de fenômenos culturais que as pessoas vivem, mas não costumam falar. Falam sobre o não dito, advogando contra determinadas invisibilidades e silenciamentos, ao mesmo tempo em que ressaltam a importância da narração, em especial da narração pessoal, nas ciências humanas e sociais. Para ele,

aquelas com aspirações autoetnográficas devem realmente levar as práticas de escrita e representacionais muito a sério, e considerar a escrita como um ofício no qual precisam trabalhar, como se estivessem praticando um instrumento musical para melhorar e ganhar domínio sobre ele. Então a pesquisa não é algo a ser escrito. Ao invés disto, o conhecimento é criado através da escrita: rascunho após rascunho, após rascunho, após rascunho (Grant, 2014, s/p, tradução minha)².

Sendo um conhecimento criado através da narração (verbal, mas também através de outros meios), é uma forma de produzir conhecimento que se engaja profundamente com práticas representacionais e éticas: o uso da metáfora, de textos confusos, da escrita experimental, as formas poéticas e a ruptura do tempo linear são alguns dos dispositivos que caracterizam trabalhos autoetnográficos contemporâneos (Grant, 2014). Ao desafiarem as normas e fronteiras representa-
2 Texto original: "Those with aspirations towards autoethnography should take writing and representational practices very seriously indeed and regard writing as a craft they need to work at, just as if they were practising a musical instrument in order to improve and gain mastery over it. So research is not written up. Instead, knowledge is created through writing: draft after draft after draft after draft" (Grant, $2014, s / p)$ 
cionais e experimentar com as formas, estruturas e conteúdos, trabalhos autoetnográficos investem na expressão das emoções como uma forma de abordagem cultural e apresentam como autoras pessoas encarnadas. Dessa forma, eles ampliam o que se pode dizer sobre determinados assuntos, pessoas e instituições, e até mesmo sobre a disciplina antropológica.

Neste sentido, e por serem frutos de uma combinação de métodos, sujeitos, conceitos, políticas e teorias que não podem ser separados, são trabalhos especialmente interessantes no que diz respeito a situações de vulnerabilidade (Costa, 2016). Isto ocorre porque, neles, além de refletirmos sobre dados observados externamente e relatados oralmente, também atentamos para conhecimentos apreendidos através do nosso próprio corpo, que se move e encontra diferentes ambientes, pessoas, objetos e experimenta diversas emoções.

Para algumas autoras, a autoetnografia é um gênero; para outras, um método. Para Daniela Versiani (2005, p. 16), ela seria "um conceito em construção, sobre o qual não há definições e compreensões estabilizadas". Um conceito que operaria na interseção entre termos de pares dicotômicos, como "auto" e "etno", "numa tentativa de criar condições cognitivas de apreensão da relação entre os dois não de modo alternado e/ou oposto, mas sim concomitante, simultâneo, relacional” (Versiani, 2005, p. 2013).

Se não há consenso no que diz respeito ao que é uma autoetnografia, em resenha sobre o Handbookof Autoethnography organizado por Holman-Jones, Adams e Ellis (2013), Pedro Motta e Nelson Filice de Barros (2015, p. 1339) apontam para algumas características dos trabalhos autoetnográficos. De acordo com eles, tais trabalhos investem em: 1 ) visibilidades para o si (a pesquisadora se torna visível no processo, em relação com ambiente, as pessoas etc.); 2) fortes reflexividades; 3 ) engajamentos ("em contraste com a pesquisa positivista que assume a necessidade de separação e objetividade, a autoetnografia clama pelo engajamento pessoal como meio para entender e comunicar uma visão crítica da realidade"); 4) vulnerabilidades (explora fraquezas, forças e ambivalências da pesquisadora); 5) rejeita conclusões ("é concebida como algo relacional, processual e mutável”).

Não tratamos de "dados”, mas de "experiências". São pesquisas altamente corporificadas, reflexivas e emotivas - qualidades muitas vezes criticadas ou ignoradas nas pesquisas qualitativas, mesmo antropológicas - e por isso transgressoras, indisciplinadas, políticas.

Para muitos de nós, não basta apenas escrever ou falar sobre nossos assuntos. Estamos condenados a vivê-los - ao menos o tanto quanto podemos, às vezes porque atuamos como estudiososde determinados pontos de vista ou movimentos emnossas áreas de pesquisa, em vez de, para emprestar um termo de Frank Furedi (2004), sermos simples tecnocratas educacionais. Para algumas audiências reais e virtuais, isso pode ser cativante, envolvente e conectado, enquanto para outros isso pode confirmar o quão maus, rebeldes, perigosos, indisciplinados e não acadêmicos muitos de nós somos, 
com falta de distanciamento, equilíbrio e objetividade (Grant, 2014, s/p, tradução minha) $)^{3}$.

Esta pesquisa é fruto de experiências e diálogos vividos no encontro com outras pacientes, aparatos, pessoas e instituições da saúde. Ela foi realizada num lugar de estranhamento em que me vi quando, realizando pós-doutorado em antropologia, com um interesse especial por reflexões sobre emoções e sensorialidades, passei a experimentar um universo de possibilidades nunca antes experimentado. Tais experiências vividas intensamente no primeiro ano do diagnóstico, enquanto ministrava disciplinas sobre métodos de pesquisa qualitativa e antropologia visual, assim como o estímulo incansável de uma colega da Universidade de Brasília especialista em antropologia da saúde, a professora Soraya Fleischer, lançaram-me a produzir textos, imagens e questionamentos a partir de um lugar de fala privilegiado, enquanto pesquisadora e paciente.

Nesta pesquisa, diversos métodos qualitativos de pesquisa antropológica foram utilizados: observação participante, entrevistas abertas, histórias de vida, pesquisa online, fotoetnografia, análise de imagens e discursos, entre outros. As imagens foram produzidas em diversos momentos: para registrar e refletir sobre os processos vividos, e para apresentar "dados" da pesquisa (Guran, 2000). Elas também foram produzidas por outras pessoas (técnicas da saúde) sobre mim.

O trabalho de campo aconteceu enquanto eu refletia sobre as experiências que vivia, mas também a partir da análise de sites e blogs de pacientes, médicos e pesquisadores de esclerose múltipla e/ou doenças crônicas na Internet, em páginas no Facebook dedicadas à esclerose múltipla e ao medicamento que tomo, em grupos do WhatsApp de pacientes, e em diversos outros locais (eventos, consultas, exames, internações hospitalares, no SUS etc.).

O campo, assim, se deu fisicamente (em meu corpo e nos diferentes ambientes que circulei) e virtualmente. Ele aconteceu em Brasília, cidade onde eu vivia e trabalhava em 2015; no Rio de Janeiro, onde vivia minha família e onde recebi a maior parte dos tratamentos; e em São Paulo, onde busquei tratamentos alternativos.

\section{Esclerosada: da imaginação social à pessoal}

O progresso da minha doença não foi nem rápido nem dramático, e seu efeito mais profundo foi em minha consciência, minha autoconsciência, a forma como eu apreendi e construí o mundo e minha posição nele (Murphy, 1987 , p. 13, tradução minha) $)^{4}$.

Em 2014 fui diagnosticada com esclerose múltipla, uma doença neurológica crônica autoimune pouco conhecida: não se sabe ao certo o que a causa e ela não tem cura. De acordo com nossa medicina, trata-se de uma doença inflamatória em que as células do sistema imunológico atacam o sistema nervoso central (cérebro, medula espinhal e nervo óptico). Tal ataque é desencadeado como uma resposta a algum vírus, bactéria ou mesmo ao estresse, e causa danos à bainha de mielina, a
3 Texto original: "For many of us, it's not enough just to write it, or talk about our topics. We are condemned to live them - at least as much as we can, sometimes because we function as standpoint or movement scholars for our research areas, rather than, to borrow a term from Frank Furedi (2004), simply educational technocrats. For some real and virtual audiences, this can be endearing, engaging and connecting, while for others it can confirm what a bad, unruly, dangerous, undisciplined and unscholarly lot we are, lacking distance, balance and objectivity" (Grant, 2014, $\mathrm{s} / \mathrm{p})$.

4 Texto original: "The progress of my illness was neither rapid nor dramatic, and its most profound effect was upon my consciousness, my self-awareness, the way I apprehended and constructed the world and my position in it" (Murphy, 1987, p. 13). 
Fabiene Gama

cobertura protetora das células nervosas que, danificada, retarda e/ou interrompe os impulsos nervosos para partes do corpo (Fuller, 2015).

Seus sintomas são extremamente variáveis e dependem da localização e da gravidade de cada ataque inflamatório, chamado de surto. Podem ser: dormência, dor, formigamento, perda de equilíbrio e coordenação, dificuldade para caminhar, transtornos visuais, incontinência intestinal e urinária, diminuição da capacidade de atenção, perda de memória, transtornos fonoaudiólogos, cognitivos e emocionais, fadiga, entre outros. Ou seja, uma gama imensa de alterações motoras, sensitivas, visuais e cognitivas, que podem ser temporárias ou permanentes. $\mathrm{O}$ diagnóstico da doença é feito através de um exame clínico combinado com outros laboratoriais, que na maior parte das vezes serve para descartar outras doenças. Desses exames, o mais importante é a ressonância magnética, um exame que cria imagens de alta definição de órgãos internos através de um campo magnético.

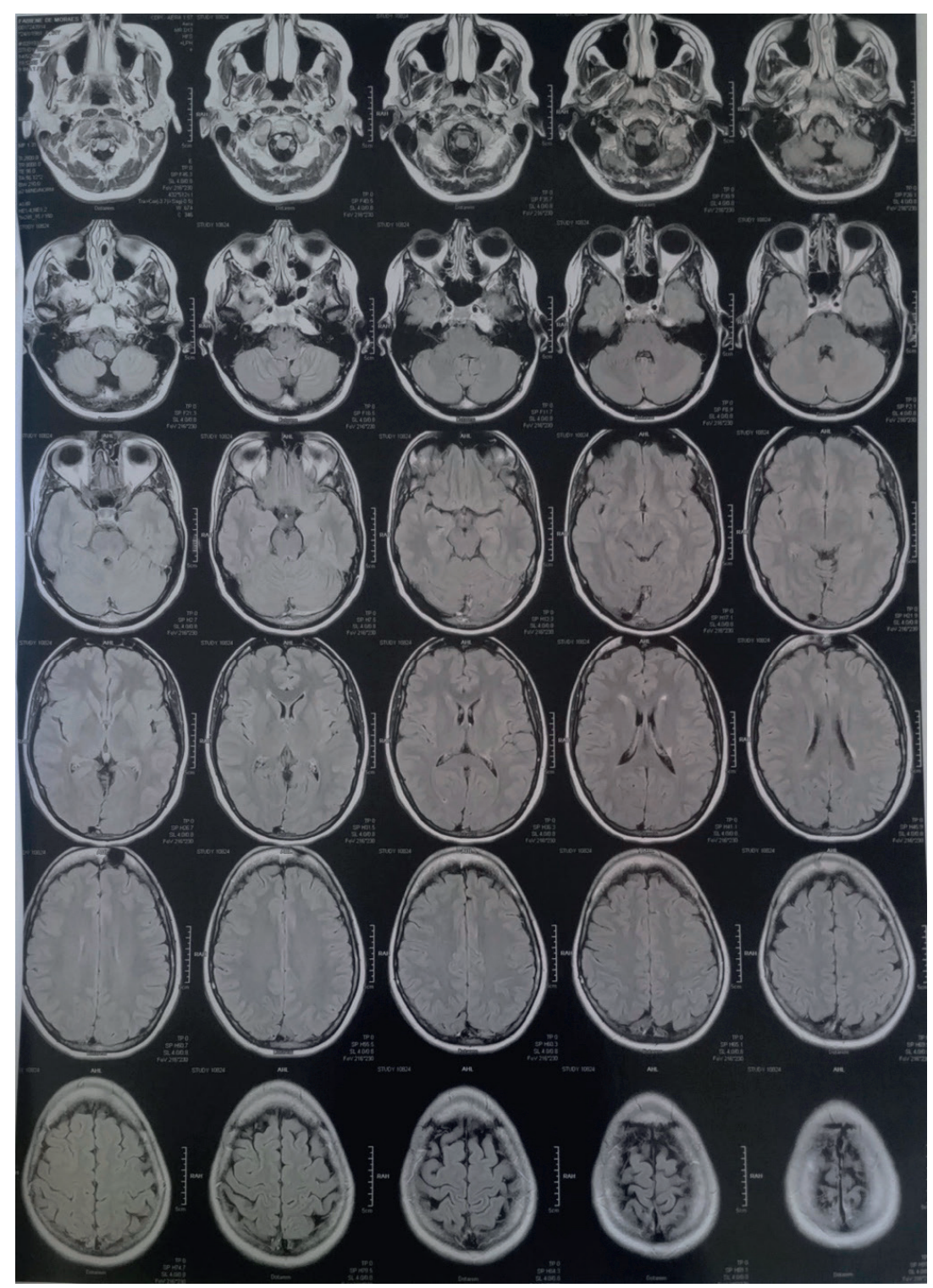

Primeira ressonância magnética e a descoberta do interior do crânio. 
De acordo com Fuller (2015), para diagnosticar uma paciente com esclerose múltipla, uma médica deve: 1) encontrar evidências de danos ou lesões em pelo menos dois locais separados no sistema nervoso central, 2) encontrar evidências de que os danos ou lesões ocorreram com pelo menos um mês de intervalo, e 3) descartar todos os outros diagnósticos possíveis. As lesões do sistema nervoso central devem estar disseminadas no espaço e no tempo, ou seja, devem ter acontecido em locais e momentos diferentes. $\mathrm{O}$ aparecimento e o desenvolvimento da esclerose múltipla em uma pessoa, contudo, é variável e em grande parte imprevisível, tornando um prognóstico impossível. A doença pode permanecer em remissão (adormecida) por breves ou longos períodos, e apresentar um número variado de surtos (inflamações/recaídas) ao longo da vida, com sintomas diversos.

Um dado importante do desenvolvimento da doença é que um surto é sempre diferente do outro. Ou seja, sua experiência é sempre nova. Uma pessoa pode acordar cega um dia, e depois de um período (imprevisível) de tempo voltar a enxergar, ou não. Em outro momento acordar sem o movimento de uma das pernas e após certo tempo voltar a movimentá-la, ou não. Tais sintomas também podem ser sentidos novamente devido a fatores externos (como o calor) ou internos (o estresse), sem que configurem um novo surto. Mas no local onde se formou uma cicatriz, uma inflamação não volta a acontecer. A doença também pode se desenvolver com uma piora progressiva ao longo do tempo, sem recaídas reconhecíveis ou com surtos periódicos, sendo atualmente classificada de quatro formas: 1) surto-remitente ou remitente-recorrente, 2) primária-progressiva, 3) secundária-progressiva e 4) progressiva-recorrente.

O tempo médio para o diagnóstico de uma pessoa com esclerose múltipla é de sete anos. O meu diagnóstico, contudo, foi fechado em apenas dois meses. Isto se deu graças à minha atenção ao meu corpo e também à sorte de ter encontrando uma neurologista que foi atenta aos meus relatos, solicitando os exames necessários para o diagnóstico correto do problema. Até chegar a ela, uma decisão tomada sem qualquer recomendação médica, eu havia procurado clínicos gerais e médicos especialistas nos sintomas que eu sentia e nenhum deles - todos homens - cogitaram uma doença neurológica. Todos, sem exceção, diziam que o que eu sentia era fruto do "estresse" - essa coisa abstrata que parece ser a atualização contemporânea do que foi chamado de histeria em outros tempos.

Ao ser diagnosticada com esclerose múltipla, passei a buscar informações sobre a doença na Internet e nas diversas consultas médicas pelas quais passava. Não sabia nada sobre doenças crônicas, menos ainda sobre esta esclerose múltipla. Imaginava que pudesse ter a ver com algum tipo de demência, como muitas pessoas. As informações que eu encontrava, contudo, ou mobilizavam linguagem médica de difícil compreensão, ou eram confusas, até mesmo contraditórias. Em alguns sites, por exemplo, li que uma pessoa diagnosticada com esclerose múltipla recorrente-remitente (o meu tipo) poderia viver com uma qualidade de vida "normal" devido às medicações modernas. Em outros, li que, com o passar dos anos, uma pessoa diagnosticada com a doença poderia ter uma evolução deste tipo para um tipo mais grave e incapacitante, chamado de secundária progressiva. 
FABIENE DE MORAES VASCONCELOS GAMA, sofre de Esclerose Múltipla recorrente-remitente, com Bandas Oligoclonais positivas no liquor preenchendo critérios de McDonald et al., 2011 desde $o$ inicio da doença. Evoluiu e vem evoluindo com surto de mielite cervical, nivel sensitivo em hemitronco. Tem AQP4 (-), e RM com múltiplas lesões que captavam gadolineo, fator altamente preditivo de evolução para incapacidade motora e progressão da doença.

Trecho do primeiro laudo médico: "Fabiene (...) sofre”.

McDonald? Hemitronco? AQP4(-)? Evolução para incapacidade?

Nos encontros com diferentes neurologistas (foram sete no primeiro ano), eu buscava, além de encaminhamentos, esclarecimentos. Mas saía das consultas frequentemente frustrada: as médicas raramente estavam dispostas a compartilhar o conhecimento e, especialmente, as tomadas de decisão. Ainda que os sintomas da esclerose múltipla sejam diagnosticados essencialmente através do exame clínico e de relatos das pacientes, poucas médicas estão dispostas a levar a sério suas narrativas dos pacientes a fim de "reconhecer, assimilar, interpretar e ser tocado pelas histórias das doenças" (Charon, 2006, p. vii, tradução minha). Ainda que as médicas precisem dos relatos das pacientes para sugerir o melhor tratamento, ao contrário do que fazemos em nossa prática antropológica, as médicas geralmente se recusam a construir o resultado do seu trabalho de forma compartilhada: partem do princípio de que pacientes são ignorantes. Podemos perceber isto no relato apresentado em outra autoetnografia, de Costa, em Portugal:

Sob a pressão do conjunto de sintomas que apresentei em termos gerais, dirigi-me ao Centro de Saúde a uma consulta de urgência - que é muito útil em situações em que não se dispõe de médico de família. Lá encontrei uma médica precisamente oriunda de Leste e, agora, era eu que, no meu próprio país, tinha dificuldade em compreender o que a médica dizia. Este encontro foi em vários aspetos traumático. Quando a médica, no seu português arranhado, me perguntou de que me queixava, eu disse que tinha muito sono e me sentia inchado, e que tinha sentido maior intensidade nos sintomas desde que tinha tomado a vacina antitetânica. De modo direto, a médica negou qualquer relação com a vacina, chamando-me, agora com clareza, "ignorante" (Costa, 2016, p. 282).

Os traumas experimentados nos encontros médicos na busca por tratamentos foram múltiplos e definiram, para mim, o que significava ser cronicamente doente. Essa aprendizagem ocorreu intelectual, mas também física e emocionalmente: aprendi como me comportar e como e com quem falar nos diversos ambientes em que circulava. Apesar da minha enorme vontade de compreender o que acontecia e tomar as decisões sobre meu corpo, minha saúde ou mesmo sobre minha vida, afinal os remédios impactam diferentes esferas da existência, minha agência era 
frequentemente negada. Eu deveria confiar nos médicos, seguir suas recomendações, aceitar o diagnóstico e os tratamentos. Um comportamento que eu tinha dificuldades de ter, muito diferente das minhas experiências anteriores. Decidi então documentar e refletir sobre tais experiências.

Através dos diversos exames, tratamentos, internações, encontros com enfermeiras, médicas, técnicas de enfermagem, e de visitas a hospitais, consultórios, laboratórios, eu fui tomando consciência de uma nova identidade: a de uma doente crônica. Tal experiência provocou mudanças na minha autoimagem, como apontado acima por Murphy (1987), e trouxe questionamentos a respeito de mim mesma: iria a esclerose múltipla me definir a partir daquele momento ou seria ela incorporada às minhas outras diversas identidades?

Para Fuller,a aceitação do diagnóstico da esclerose múltipla é um processo longo e difícil, que envolve a redefinição do self, a construção da confiança na identificação com uma doença crônica, e a compreensão de como se relacionar com um mundo que não entende imediatamente as necessidades e acomodações que uma pessoa com esclerose múltipla pode exigir. Grande parte do foco das pessoas com esclerose múltipla está em como um indivíduo pode lidar com o diagnóstico e superar as dificuldade da transição de ser alguém saudável para alguém com uma doença crônica. A transição pode ser feita psicologicamente ou espiritualmente (Fuller, 2015, p. 19, tradução minha) $)^{5}$.

A literatura sobre esclerose múltipla falha ao lidar com o lado socioemocional da doença, focando em seus fatores biológicos. Quando fui diagnosticada, encontrei algumas informações sobre estas novas dificuldades em blogs de pacientes ativistas, grupos do Facebook e páginas dedicadas a doenças autoimunes. Encontrei um trabalho ou outro na área da psicologia e da terapia ocupacional, mas nenhuma publicação antropológica.

De acordo com Diniz (2012), há dois modelos conflituosos sobre a deficiência, que precisamos notar: o modelo médico, que entende a lesão no corpo como deficiência; e o modelo social, que defende que a deficiência está relacionada a limitações socioambientais impostas às pessoas com alguma lesão no corpo. Em uma sociedade adaptada às necessidades dos diferentes corpos, poderia haver corpos lesionados não deficientes. As lesões, por sua vez, costumam ser legitimadas quando visíveis, tornando doenças crônicas - invisíveis - difíceis de serem compreendidas.

A preservação do self e da identidade em pessoas com uma doença crônica se torna ainda complexa com a esclerose múltipla, porque muitos dos sintomas neurológicos da esclerose múltipla, como a fadiga, a perda da visão ou a dormência são invisíveis para os outros. Diferente daqueles com deficiências óbvias, pessoas com esclerose múltipla pode frequentemente escolher se mantêm suas deficiências escondidas ou não (Fuller, 2015, p. 19). ${ }^{6}$
5 Texto original: "Acceptance of the diagnosis of MS is a long and difficult process that involves redefinition of self, building confidence in identifying with a chronic illness, and understanding how to relate to a world that does not immediately comprehend the needs or accommodations a person with MS may require. Much of the focus for those with MS is on how the individual can cope with the diagnosis and rise above the difficulty in transitioning from a healthy individual to one with chronic illness. The transition can be made psychologically or spiritually"(Fuller, 2015, p. 19).

6 Texto original: "The preservation of self and identity in persons with a chronic illness becomes even more complex with MS because many of the neurologic symptoms of MS, such as fatigue, loss of vision, or numbness, are invisible to others. Unlike those with obvious disabilities, people with MS can often choose whether or not to keep their disabilities hidden" (FULLER, 2015, p. 19). 
Sem possuir limitações motoras, desde 2014 sinto fadiga, por vezes fraquezas e fortes dores no corpo. Tais sensações passaram a impactar minha rotina, exigindo pausas, diminuição de atividades, cuidados. Tais ajustes, no começo, custavam-me muito. Sempre fui muito ativa. Aceitar as novas limitações era mais difícil que explicá-las para os outros. E eu sentia que verbalizá-las era importante para que as pessoas as "enxergassem". Possuir uma doença com sintomas não visíveis, como cansaço, dores, formigamentos, perdas visuais etc., pode ser positivo - nos preserva de preconceitos -, mas também extremamente negativo, mesmo violento, pois há pessoas que assumem que determinadas necessidades são exageradas.

Compreender o que é a esclerose múltipla e compartilhar o conhecimento sobre esta doença, desse modo, tornou-se fundamental para mim, pois, como ressaltou Webster (1998),

diante de uma total inabilidade de controlar o que estava acontecendo, estar razoavelmente confortável em ter uma doença crônica era uma tarefa individual, algo a ser vivido em isolamento. Mas uma doença crônica não é apenas definida pela sociedade, ela é experimentada através das estruturas mediadoras da sociedade e da cultura (Webster, 1998, s/p, tradução minha) $)^{7}$.

Sendo uma experiência mediada pelas estruturas da sociedade e da cultura, tornei-me atenta aos mecanismos que transformam uma pessoa em uma doente crônica, ou mesmo em uma paciente, tais como as consultas médicas, as internações hospitalares, os exames de rotina, o medicamento de uso contínuo. Descreverei a seguir como algumas dessas experiências me afetaram.

\section{Tornando-me im-paciente}

Foi no meu aniversário de 34 anos que percebi os primeiros sintomas da doença: um cansaço extremo e uma dor no ouvido que foi se tornando insuportável. Em um primeiro momento, pensei que eram sintomas de uma otite e procurei um otorrinolaringologista. Foi quando a maratona começou. Constatando que tudo aparentava bem, apesar de eu relatar que a dor já irradiava para a lateral esquerda do meu rosto, o médico recomendou uma consulta com uma dentista: poderia ser bruxismo, fruto do "estresse", disse ele. A suspeita me surpreendeu, pois não me sentia estressada. Mas decidi investigar. Marquei uma dentista, que me recomendou um especialista em DTM - especialidade que eu não conhecia e não sabia sequer como encontrar. Iniciaram-se os problemas com as linguagens.

Sem encontrar um especialista na área, e com os sintomas se estendendo para meu couro cabeludo e ombro esquerdo, decidi procurar um clínico geral. Nesse momento, eu sentia uma coceira intensa na cabeça e achava que poderia estar também com uma alergia. Mas o clínico igualmente pensou que fosse devido ao "estresse", e me receitou um relaxante muscular. Foi quando senti um choque dentro da cabeça, que me assustou. Eu já havia iniciado um tratamento com um acupunturista e sentido melhoras. Mas então decidi agendar uma consulta com
7 Texto original: "Faced with a total inability to control what was going on, being there in some comfort having a chronic disease was an individual task, one to be undertaken in isolation. But chronic disease is not just defined by society, it is experienced through the mediating structures of society and culture" (WEBSTER, 1998, $\mathrm{s} / \mathrm{p})$. 
uma neurologista para me assegurar de que tudo ia realmente bem. Ela solicitou uma ressonância magnética, meu primeiro exame traumático.

Sem ter conhecimento do procedimento a ser adotado, fui ao exame sozinha. Nele, fiquei cerca de uma hora dentro de uma máquina com um acesso no braço para inserção de contraste, um protetor auricular para amenizar o forte barulho do exame, e um capacete para me manter imóvel durante o período necessário. Ninguém me explicou que eu deveria respirar docemente para não interferir na imagem produzida, e não precisar refazê-la. Dentro da máquina, o som era ensurdecedor. Tão alto que vibrava em meu corpo. Variava entre o grave e agudo, rápido e repetitivamente. Chegava a durar minutos sem intervalo. A abertura da máquina para entrada do meu corpo era pequena e eu me sentia sufocada. Descobri-me claustrofóbica.

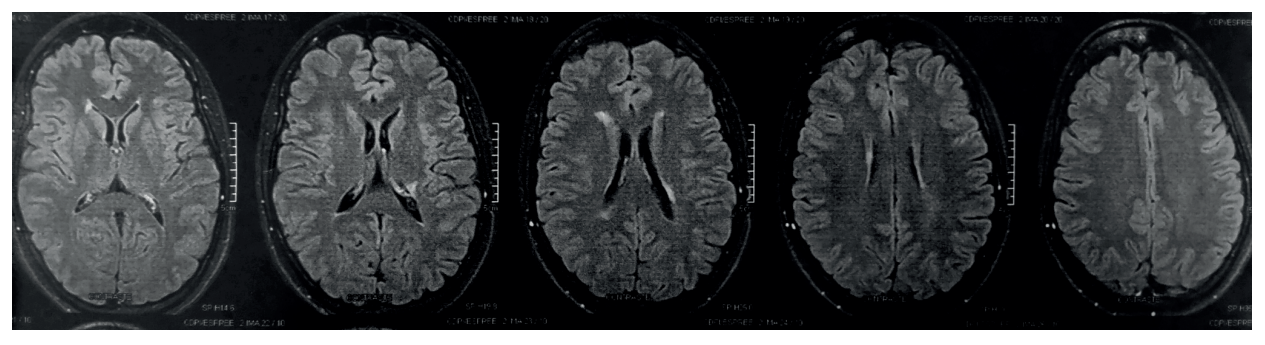

Os pontos brilhantes das inflamações ativas.

Ao voltar à neurologista com o resultado da ressonância magnética, descobri que eu tinha inflamações ativas no cérebro, no cerebelo e na coluna cervical. Havia forte indicação de que eu tinha esclerose múltipla, mas ainda era preciso descartar seis outras possibilidades. A médica recomendou uma internação hospitalar no dia seguinte para realização de uma pulsoterapia com altas doses de um corticoide, a fim de conter o processo inflamatório. Em um primeiro momento, não entendi a gravidade do problema, os sintomas já tinham passado e eu me sentia bem. A médica precisou ser incisiva: as inflamações poderiam gerar sequelas irreversíveis.

Antes e depois da minha internação, eu passei por uma série de exames altamente invasivos para verificar o estado da minha saúde, eliminar outras doenças e escolher o melhor medicamento para o meu caso. Agulhas me picavam, retirando líquidos do meu corpo. Máquinas produziam imagens de diversos órgãos: analisavam meus olhos, meu pulmão, meu coração, meu cérebro, observaram minha força, meus movimentos, meu equilíbrio. Nunca tinha sido tão mexida, por tantos desconhecidos. Os exames afetavam-me profundamente. Sentia-me invadida, abusada, desrespeitada. Tinha minha fala ignorada, meu corpo manipulado, decisões sobre minha vida tomadas por pessoas que não sabiam nada sobre mim.

O ambiente hospitalar, a instalação do acesso em meu braço para aplicação intravenosa de medicamentos que poderiam ser tomados oralmente, a obrigação de circular entre ambientes em macas, ambulâncias e cadeira de rodas, quando 
eu conseguir caminhar perfeitamente, além da necessidade de ficar trancada em um quarto com uma acompanhante, definiram a minha experiência inicial com a esclerose múltipla: significava intervenções, controle e desempoderamento.

"Uma pessoa com uma tatuagem deste tamanho não devia ter medo de agulhas", me disse um médico plantonista, quando solicitei tomar oralmente os remédios que me foram prescritos, aos quais eu tinha direito. $\mathrm{O}$ acesso à minha veia precisou ser trocado três vezes em uma semana porque minhas veias reiteradamente entupiam. Deixei o hospital cheia de hematomas, que não resultavam da pulsoterapia em si: eram fruto da maneira como meu corpo foi manipulado.

$\mathrm{O}$ gosto amargo que as altas doses do corticoide deixaram em minha boca após o tratamento simbolizou a experiência vivida. Ao tomar contato com essas novas sensações, questionei-me sobre como meu corpo funcionaria a partir do diagnóstico. Tive medo de me tornar dependente, inválida, frígida, deprimida. Eu não me identificava com nenhuma dessas características.

Tanto a pulsoterapia quanto o remédio de uso contínuo que tomo para a esclerose múltipla são drogas que deprimem o sistema imunológico: ao mesmo tempo em que impedem que meu sistema imunológico me ataque, me deixam mais vulnerável a infecções, mais cansada, com mais dores, mais fraca. A fim de me fortalecer, passei a inserir em minha rotina uma série de práticas de cuidado que me ajudaram a ter mais energia, disposição e bem-estar. Eram práticas holísticas e integrativas que me mostraram fisicamente como meu corpo e minha mente trabalhavam juntos, tornando-me mais atenta aos meus sentidos. Tais práticas, como a acupuntura, a antroposofia e a Ayurveda eram frequentemente ignoradas ou mesmo menosprezadas nas consultas neurológicas que realizava. As médicas pareciam mais preocupadas com a doença que com minha saúde; e a ausência de diálogo no que dizia respeito ao meu autocuidado, frustrava-me, chegando ao extremo quando decidi engravidar.

\section{Gravidez, pesquisa e terrorismos: quando desejos da paciente resvalam na segurança médica}

Sabendo que precisaria suspender o uso do medicamento e "limpar" o corpo antes de começar a tentar engravidar, eu passei a estudar todas as opções e os riscos envolvidos nesta nova empreitada. Tornei-me ciente dos debates sobre gravidez, parto e pós-parto na esclerose múltipla, e de questões específicas relacionadas ao medicamento que tomava. Havia um consenso de que era possível engravidar e de que durante a gravidez as mulheres tenderiam a ficar mais protegidas de surtos da doença, mesmo sem tomar medicamentos ${ }^{8}$. As transformações pelas quais o corpo de uma mulher passa para proteger o feto, um corpo estranho ao organismo, durante a gravidez acabariam por proteger a própria mulher dos ataques autoimunes.

O que não era consenso estava relacionado ao que poderia acontecer antes e depois gravidez, especialmente no pós-parto. Antes da gravidez porque, ao suspender o medicamento, havia a possibilidade de um "efeito rebote" do medicamento com surtos mais fortes. Depois, porque o alto esforço e estresse do parto,
8 Ainda não havia estudos que demonstravam segurança no uso do meu medicamento durante a gravidez, e por isso precisei suspendê-lo. 
assim como as grandes alterações hormonais do evento e do que se segue, poderiam colaborar com um quadro propício a surtos da doença.

Os neurologistas, de uma forma geral, acreditavam que seria mais "seguro" para mim trocar o medicamento de uso contínuo por outro que fosse permitido durante a gravidez, ou ao menos até conseguir engravidar (tempo indeterminado), suspendendo o tratamento em seguida. Isso significaria uma nova adaptação a um novo medicamento, algo que não é simples física nem emocionalmente - sem falarmos de toda a burocracia e gasto financeiro envolvido. Outra opção seria fazer uma nova pulsoterapia com corticoides, algo que serviria apenas para debilitar meu sistema imunológico, deixando-me enfraquecida e assim menos suscetível a uma hiperatividade do meu sistema imunológico. Uma espécie de "prevenção" para algo "imprevisível”, uma coisa que não fazia qualquer sentido para mim. Especialmente porque no caso de um surto da doença, o tratamento seria o mesmo, uma pulsoterapia. Era fazer sem ter um problema, ou deixar para fazer apenas se houvesse um. Optei pela segunda opção e suspendi o medicamento sem substituí-lo por nenhum outro.

Compreendendo que o pior que poderia acontecer, dadas as características da minha esclerose múltipla, seria me deparar com um novo surto, decidi arriscar. Estava forte e segura da minha saúde devido aos cuidados que já mantinha há cerca de um ano. Nada aconteceu, engravidei na primeira tentativa logo após o período de "limpeza" do medicamento, exatamente dois meses depois da sua suspensão.

Neste processo tive apoio de um único neurologista com quem podia conversar, apresentar medos e receios, e receber o apoio de que precisava para tomar minhas decisões, sempre embasadas nos debates contemporâneos da medicina. Durante a gravidez, contudo, mudei de cidade e precisei procurar uma nova equipe médica: obstetra, neurologista, clínica geral etc. Vivendo agora em uma cidade menor e mais conservadora que o Rio de Janeiro, passei por encontros realmente traumáticos na busca por um acompanhamento que seguisse respeitando minhas escolhas. Decidida a amamentar a minha filha nos seus primeiros seis meses de vida, encontrei médicas absolutamente intransigentes, que se recusavam a me acompanhar neste processo.

"Você deve retomar seu medicamento no dia em que parir sua filha", me disse o primeiro neurologista que consultei. "De outro modo você vai colocar sua vida e a dela em risco. Com quem ela ficará se você precisar ficar internada?” Entre uma pergunta e outra, ele perguntava ao meu marido para qual time de futebol ele torcia. Seria um procedimento muito simples, ele dizia, "você aproveita que já vai estar no hospital e, depois que sua filha nascer, faz uma pulsoterapia e retoma o remédio". Eu pensava no momento do parto e na minha experiência anterior de pulsoterapia, nos hematomas, nas dores no corpo, na fraqueza que senti. Pensava no que imaginava ser um pós-parto e todas as dificuldades que tinha ciência de que poderia enfrentar. Eram experiências que simplesmente não cabiam juntas, em mim.

"Você deve retomar o medicamento logo após o parto", me disse também a segunda neurologista que consultei. "Você não precisa fazer uma nova pulsoterapia, e pode até esperar alguns dias antes de retomar o medicamento. Mas não 
recomendo a amamentação, seria muito arriscado. Você vai querer arriscar? Como você ficará se não puder pegar sua filha em seus braços? Não será pior ter que ficar longe dela, hospitalizada, do que simplesmente retomar a medicação e garantir que você poderá cuidar dela quando ela nascer?”

A ideia de não poder segurar minha filha em meus braços, e que eu não pudesse cuidar dela depois do seu nascimento era realmente horrível. Eu saía aos prantos de cada consulta, amamentar era algo que eu realmente queria fazer. $\mathrm{E}$ sabia, racionalmente, que poderia. Eu já tinha lido muito sobre amamentação e esclerose múltipla, já tinha conversado com outras mães que têm a mesma doença e participava de grupos sobre o tema no Facebook. Mas emocionalmente eu estava muito diferente de antes da gravidez, quando as decisões que tomava produziam riscos apenas para mim mesma. Agora envolviam também a vida de uma bebê. $\mathrm{E}$ obviamente eu queria o melhor para ela.

Apesar de abalada e frustrada, por vezes aterrorizada, por não conseguir uma neurologista que respeitasse minhas escolhas nesta nova cidade, decidi seguir com meus planos e manter meu neurologista no Rio como apoio em caso de alguma necessidade. Minha filha nasceu, amamentei-a exclusivamente em seus primeiros seis meses e retomei o medicamento na sequência. Tudo correu bem. Este caso, contudo, ilustra bem os desafios enfrentados quando paciente e médicas discordam sobre os encaminhamentos dos tratamentos. Frequentemente seguimos desassistidas, ou com assistências precárias.

Preocupadas com a "segurança" em relação à doença, as médicas frequentemente ignoram os desejos das pacientes que buscam outras alternativas às apresentadas inicialmente. Mesmo ciente dos debates, dos riscos e das consequências das minhas escolhas em relação aos cuidados com a esclerose múltipla, não encontrei na maioria das consultas que tive, médicas dispostas a construir de forma conjunta os melhores tratamentos para o meu caso específico. Todas desejavam me convencer a seguir um protocolo visto como seguro para o tratamento da doença.

\section{Reflexões sobre os imponderáveis do cotidiano}

Dizem que a doença e a deficiência são condições psicológicas e sociais, assim como problemas somáticos, e isso me trouxe vividamente a mim. Pessoas em boa saúde tomam como certas suas condições e seus corpos; elas podem ver, ouvir, comer, fazer amor e respirar porque elas possuem bons órgãos em funcionamento, que podem fazer todas essas coisas. Esses órgãos, e o corpo em si, estão entre as bases sobre as quais nós construímos nosso senso de quem e o que somos, e eles são instrumentos através dos quais nós lidamos com e criamos a realidade. Como escreveu Simone de Beauvoir, a anatomia pode não ser nosso destino, mas ela é certamente uma primeira suposição, algo não declarado, em todos os nossos empreendimentos. Cada pessoa simplesmente aceita o fato de que tem duas pernas que podem andar; ela não pensa sobre isso ou se maravilha com isso, mais 
do que estaria grata pelo oxigênio presente no ar. São partes das simples condições existenciais da vida. Eu terei muito mais a dizer sobre tudo isso, mas por enquanto basta dizer que a doença nega esta falta de consciência do corpo ao guiar nossos pensamentos e ações. O corpo não pode mais ser dado como certo, implícito e axiomático, porque se tornou um problema. Ele não é mais objeto de suposições inconscientes, mas de pensamentos conscientes. E foi assim que, pela primeira vez na minha vida, eu comecei a pensar bastante sobre minha condição física. Eu estava me tornando bem autoconsciente e de um modo bem desagradável (Murphy,1987, p. 12-13)9.

Ao ser diagnosticada com uma doença crônica, um fato importante passa a conduzir a vida de uma pessoa: a preocupação com o tratamento e o controle da doença. No primeiro ano do meu diagnóstico, além de ingerir diariamente uma cápsula do medicamento de uso contínuo, eu precisei fazer hemogramas mensais, exames cognitivos, de força, ressonâncias magnéticas, exames de fundo de olho etc. Alguns foram feitos para avaliar o risco do medicamento, outros para investigar efeitos dele e da doença.

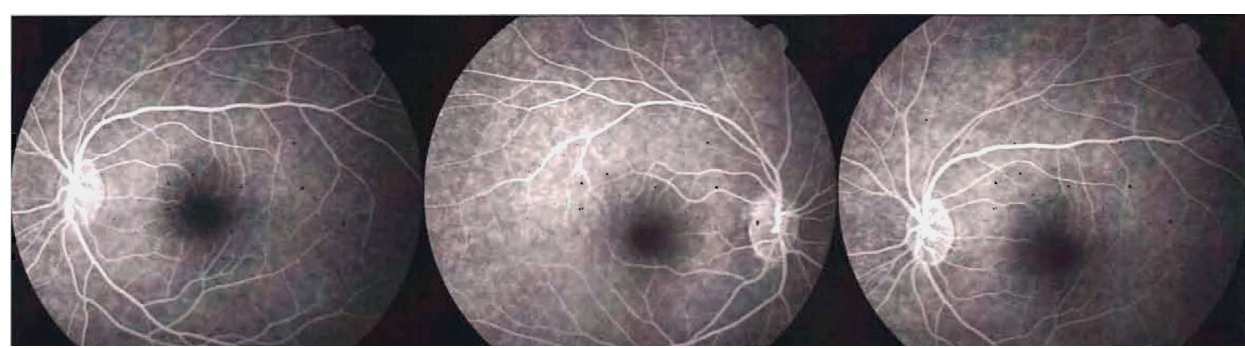

Retinografia e o fundo do olho

A retinografia, um exame realizado em substituição ao O.C.T. (tomografia de coerência óptica) não autorizado pelo plano de saúde, foi especialmente traumática. O objetivo era investigar a incidência de edema macular, um efeito colateral do medicamento. Sofrendo de fotofobia, eu tive dificuldades em manter as pálpebras abertas durante o exame, que consistia no registro de fotografias com flash dos olhos dilatados. A fim de realizá-lo, fixaram minhas pálpebras abertas com esparadrapos. Lágrimas escorriam dos meus olhos enquanto a pessoa que realizava o procedimento perdia a paciência com a longa demora para realizar o exame.

Os exames não ficam mais fáceis ao longo dos anos. Mas pacientes desenvolvem estratégias para lidar com eles. Se nas primeiras experiências eu era surpreendida a cada novo procedimento, nos anos seguintes eu escolhia até aonde iria com as investigações. Para as ressonâncias magnéticas, que após o diagnóstico chegaram a durar mais de duas horas, por exemplo, passei a ir acompanhada e tomar um ansiolítico para suportar, imóvel, o tempo dentro da máquina. A indicação de novos remédios para conter os efeitos de outros, ou de exames, era uma prática recorrente nas consultas médicas realizadas.
9 Texto original: "Illness and impairment, we are told, are psychological and social conditions as well as somatic problems, and this came home to me vividly. People in good health take their lot, and their bodies, for granted; they can see, hear, eat, make love, and breathe because they have good working organs that can do all those things. These organs, and the body itself, are among the foundations upon which we build our sense of who and what we are, and they are instruments through which we grapple with and create reality. As Simone de Beauvoir wrote, anatomy may not be destiny, but it is indeed an unstated first assumption in all of our enterprises. Each person simply accepts the fact that he has two legs and can walk; he does not think about it or marvel at it any more than he would feel gratitude for the oxygen content of air. These are among the simple existential conditions of life. I will have much more to say about all this, but for now it need only be said that illness negates this lack of awareness of the body in guiding our thoughts and actions. The body no longer can be taken for granted, implicit and axiomatic, for it has become a problem. It no longer is the subject of unconscious assumption, but the object of conscious thought. And so it was that, for the first time in my life, I began to think a great deal about my physical condition. I was becoming quite self-conscious, and in a very unpleasant way" (MURPHY, 1987, p. 12-13). 
Todos esses procedimentos e as relações que eles envolviam me transformaram profundamente e me colocaram em um estado de alerta em relação ao meu corpo. Hoje, eu preciso ser capaz de compreender e explicar o que acontece dentro de mim para as diferentes especialistas que consulto. E também para tomar minhas decisões sobre que tipo de exame é imprescindível realizar ou não. Em minha vida cotidiana, também preciso reconhecer os meus novos limites. Como ressaltou Murphy (1987, p. 13), a doença nega a falta de consciência sobre o corpo ao guiar nossos pensamentos e ações, pois o corpo se torna um problema.

Este trabalho resultou de uma dupla jornada: acadêmica, de reflexões sobre autorrepresentações, fotografias, ativismos, performances e emoções (Gama, 2016; 2009); e pessoal, que diz respeito à minha experiência com o diagnóstico da esclerose múltipla. Digo "diagnóstico" e não "doença", pois foram as relações com os médicos, exames, tratamentos, instituições que desencadearam as considerações aqui apresentadas, ainda que as minhas experiências com os sintomas da doença tenham me colocado em determinado "estado de espírito" capaz de desenvolver tais ponderações.

Aprender a observar as necessidades e sensibilidades do meu sistema nervoso central tornou-me atenta a sutilezas antes despercebidas, pois agora eu preciso entender exatamente o que sinto para ser capaz de explicar, e também para saber que tipo de ajuda buscar. Mas foram minhas reflexões antropológicas e os diálogos (ou a falta deles) com as diversas especialistas que encontrei que permitiram as análises aqui apresentadas. E foram muitas: neurologistas em diferentes estados do Brasil, desenvolvendo diferentes tipos de tratamentos, fisioterapeutas, terapeutas ocupacionais, clínicos gerais, enfermeiras, técnicas em enfermagem, dentistas, ginecologistas, otorrinolaringologistas etc.

Sem ter conhecimento da linguagem médica e dos procedimentos médicos e legais a serem realizados - muita papelada precisava ser preenchida e encaminhada, tanto para o plano de saúde para realização de exames/tratamentos, quanto para o SUS para obtenção do medicamento -, ter uma irmã médica e outra advogada foram um privilégio que poucas pessoas possuem. Elas me explicavam a todo momento o que significava cada palavra e caminho a ser tomado. Muitas vezes mediavam tais ações, poupando-me do estresse que, se antes eu não sentia, neste processo passei a sentir.

Isto foi uma regalia que a maioria das pessoas diagnosticadas com esclerose múltipla não possui, passando pelos diferentes processos de forma bem mais lenta e sofrida. Perdidas entre os diversos procedimentos, sem apoio especializado, as pessoas enfrentam a escassez de informações sobre a doença e a falta de conhecimento médico, de forma que o próprio diagnóstico se torna difícil. A maior parte das pessoas não entende os sintomas e não sabe que médica procurar. Com todo o apoio que recebi, contudo, ainda foram precisos meses para que eu finalmente pudesse me apropriar dos termos médicos e jurídicos a ponto de ser capaz de usá-los. Ainda hoje, depois de consultar muitas médicas, pacientes, grupos de pessoas com esclerose múltipla e de usuárias do mesmo medicamento que eu, textos, vídeos, fotos, debates, palestras, sites etc., sigo buscando, sem 
muito sucesso, interlocuções na área da saúde capazes de me empoderar como uma paciente ativa.

Esta dificuldade está relacionada, em parte, ao fato de que as médicas acreditam que possuir um conhecimento especializado as torna mais aptas a decidirem os melhores encaminhamentos; mas também, em parte, por causa da "responsabilidade civil da médica", que as torna legalmente responsáveis pelos tratamentos recomendados (Lamachia; Gonçalves, 2018).

\section{Autocuidados e cuidados médicos}

O diagnóstico da esclerose múltipla me levou a conhecer a história de Laura Pires (Pessoa, 2013), uma mulher diagnosticada com a doença há mais de dez anos, que buscou tratamento para a doença na medicina tradicional indiana, a Ayurveda. Tal medicina vê a doença como um desequilíbrio do corpo, que é pensado como um complexo corpo-mente-alma, e não como fruto de um órgão ou sistema defeituoso. E para reestabelecer a saúde - e não mitigar uma doença - de uma pessoa, uma médica indica uma série de tratamentos e(auto)cuidados diários voltados para aquela pessoa específica. São práticas de limpeza e nutrição (lavagem nasal, oleação corporal, yoga, pranayamas, meditação, alimentação etc.) feitas em relação com a natureza. Uma relação de continuidade com o ambiente, e não de oposição a ele ou dominação dele.

Fragilizada após o primeiro ano de tratamentos, procurei um terapeuta que me ajudou a adaptar minha rotina às práticas da Ayurveda. Tais cuidados trouxeram muito rapidamente impactos positivos à minha sensação de bem-estar, especialmente no que dizia respeito à fadiga que eu sentia. Mas eles eram desacreditados ou mesmo ignorados pela neurologista que me assistia. Enquanto eu buscava fortalecer meu corpo-mente, tornando-me agente do meu melhoramento, as médicas tendiam a dissociá-los, negando a minha capacidade de gerenciar minha doença.

Ainda que a Ayurveda tenha sido incluída na Política Nacional de Práticas Integrativas e Complementares do SUS desde o ano de 2017, ela ainda é pouco levada a sério entre a maior parte de profissionais da saúde, em especial neurologistas, que possuem relação íntima com a indústria farmacêutica ${ }^{10}$, e só veem um caminho para o tratamento de doenças crônicas neurológicas: os medicamentos. Com discursos assustadores, muitas vezes ameaçadores, como demonstrei anteriormente, muitas neurologistas que consultei defendiam que a única chance que eu teria de não ter perdas ou sequelas definitivas seria através de medicamentos alopáticos de uso contínuo. Questionando-me sobre a necessidade de tomar um medicamento que não me curaria e que poderia me causar efeitos colaterais seríssimos (bradicardia, infecções, carcinoma basocelular, edema macular, herpes zoster, entre outros), eu cogitei diversas vezes seguir sem medicação. Algo desaconselhado por todas as neurologistas que visitei, que se recusavam a acompanhar uma paciente não medicada.
10 Em diversas situações recebi amostras grátis de remédios para meus tratamentos. 


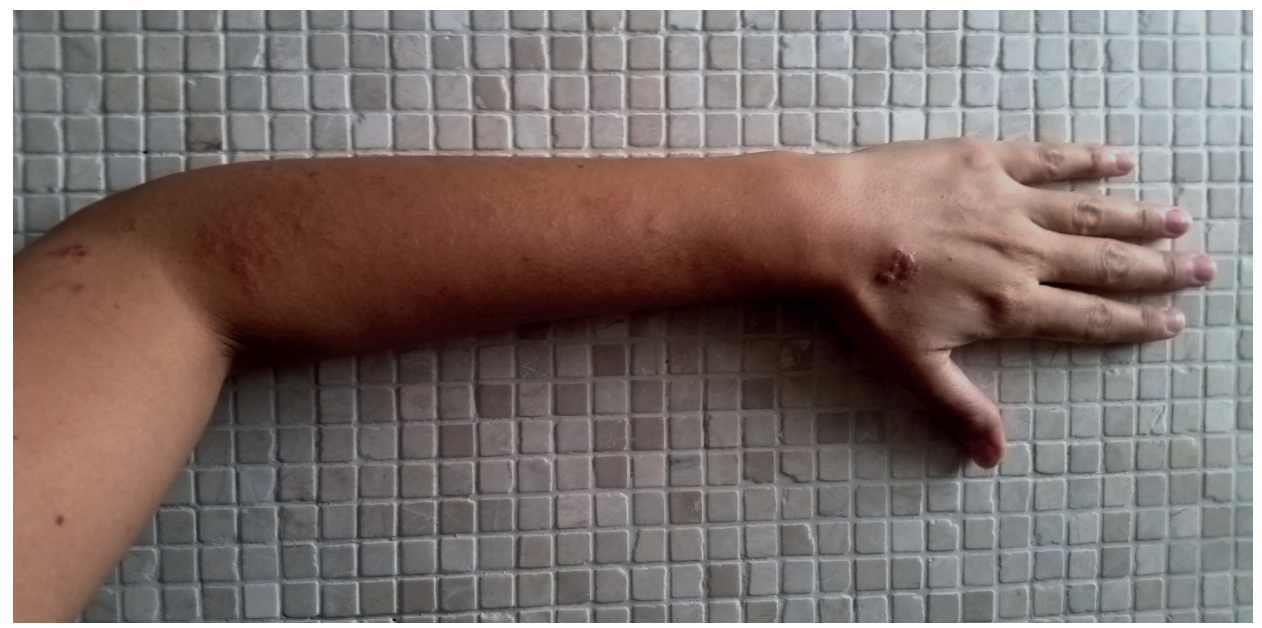

Herpes zoster: efeito colateral

Os conflitos entre essas duas formas de encontrar cuidados e olhar para doenças me levaram a compreender que, se as relações médicas-pacientes são construídas e não dadas, ainda há um hiato enorme no diálogo entre essas partes. Médicas dispostas a construir de forma compartilhada cuidados e tratamentos voltados para as necessidades de cada pacientes são raras; ainda que os benefícios desses diálogos já tenham sido comprovados cientificamente (Charon, 2006), se quisermos utilizar esta expressão cara à medicina.

A prática médica poderia ser fortalecida pelas histórias das pacientes, que convivem diariamente com seus corpos, cuidados e doenças. Mas uma prática médica compartilhada implica dividir conhecimentos e responsabilidades, além do respeito às diferenças, algo pouco discutido na formação médica (Raimondi, 2019).

Ao me dedicar a construir um conhecimento a partir da autoetnografia, mas também um tratamento que me parecesse razoável para minha doença, busquei experiências de diversas mulheres, mães ou não, com a esclerose múltipla, dentro e fora do Brasil. As histórias aqui relatadas são minhas, mas foram escolhidas a partir desses diálogos e do reconhecimento que tais experiências foram e são também vividas por muitas outras pessoas, em especial mulheres, com esclerose múltipla. $\mathrm{O}$ relato em primeira pessoa, dessa forma, não nega uma experiência coletiva, mas me coloca como parte dela.

Um ponto que parece crucial no debate sobre a relação entre profissionais da saúde e pacientes com doenças crônicas, em especial com a esclerose múltipla, diz respeito à construção compartilhada do cuidado a longo prazo. Se é verdade que em um momento de urgência é importante termos protocolos a seguir, por segurança, é também importante compreender que, ao longo do tempo, parte importante do tratamento diz respeito à experiência de cada pessoa com a doença e também com os tratamentos. E se existem pessoas que preferem delegar a responsabilidade das escolhas a médicas, várias outras preferem construir com especialistas sua forma de lidar com as doenças. Assim, poderíamos investir em relações mais acolhedoras de experiências que por si só são traumáticas. E também pensar na acessibilidade de pacientes não apenas física, mas também 
emocional e intelectualmente, a fim de desenvolver tratamentos que sejam efetivamente cuidados, e não intervenções médicas (Ayres, 2004).

Mas estar aberta para construir encaminhamentos de forma compartilhada significa se lançar em direção ao imprevisível (Gama, 2016), algo que poucas pessoas estão dispostas a fazer, por tudo o que isto implica, especialmente em termos legais, nos quais médicas ainda são vistas como tutoras de suas pacientes. Neste sentido, autoetnografias no campo da saúde configuram ferramentas de grande importância na construção de debates no campo em que diferentes perspectivas podem ser confrontadas e avaliadas, tanto na academia quanto no campo das políticas públicas e mesmo de pacientes e do público em geral que eventualmente busquem mais informações, ou simplesmente informações mais acessíveis sobre os temas trabalhados. Como forma de divulgação científica, ela traz uma peculiaridade interessante: é capaz de divulgar conhecimentos mobilizando emoções nas leitoras a fim de engajá-las de forma afetiva (ou mesmo afetada) no tema abordado.

Recebido: 23/10/2019

Aprovado: $17 / 02 / 2020$ 
Fabiene Gama

\section{Referências}

ALMEIDA, Tania M. C. A violência contra alunas: currículo oculto nos ambientes universitários. In: BIDASECA, Karina (Org.). Poéticas de los feminismos descoloniales desde el Sur.Buenos Aires: Red de Pensamiento Decolonial (RPD), 2018. p. 205-229.

AYRES, José Ricardo de Carvalho Mesquita. Cuidado e reconstrução das práticas de Saúde. Interface (Botucatu), Botucatu, v. 8, n. 14, p. 73-92, fev. 2004.

BRILHANTE, Aline V. M.; MOREIRA, Claudio. Formas, fôrmas e fragmentos: uma exploração performática e autoetnográfica das lacunas, quebras e rachaduras na produção de conhecimento acadêmico. Interface (Botucatu), v. 20, p. 1099-1113, 2016.

CHARON, Rita. Narrative medicine: honoring the stories of illness. Oxford: Oxford University Press, 2006.

COSTA, José Carlos Pinto. Para uma autoetnografia dos estados de vulnerabilidade: ensaio num caso de disfunção da tireoide. Atas do $5^{\circ}$ Congresso Ibero-americano em Investigação Qualitativa. Salamanca, Espanha, 2016.

DINIZ, Debora. O que é deficiência. 3. ed. São Paulo: Brasiliense,2012.(Coleção Primeiros Passos).

ELLIS, Carolyn; BOCHNER, Arthur P. Autoethnography, personal narrative, reflexivity. In: DENZIN, Norman K.; LINCOLN, Yvonna S. (Eds.). Handbook of qualitative research. 2. ed. Thousand Oaks, CA: Sage, 2000. p. 733-768.

FULLER, Angela. Understanding participation of racial and ethnic groups in Multiple Sclerosis Clinical Trials. Dissertação (Mestrado em Artes) - Departamento de Antropologia, San José State University, Califórnia, EUA, 2015.

GAMA, Fabiene. Etnografias, auto-representações, discursos e imagens: somando representações. In: GONÇALVES, Marco Antônio; HEAD, Scott (Orgs.). Devires imagéticos: representações/apresentações de si e do outro. Rio de Janeiro: 7 letras, 2009.

GAMA, Fabiene. Sobre emoções, imagens e os sentidos: estratégias para experimentar, documentar e expressar dados etnográficos. Revista Brasileira de Sociologia da Emoção-RBSE, v. 15, p. 116-130, 2016.

GONÇALVES, Marco Antônio Teixeira; MARQUES, Roberto; CARDOSO, Vania (Eds.). Etnobiografia: subjetividade e etnografia. Rio de Janeiro: 7letras,2013.

GRANT, Alec. Inaugural Conference of British Autoethnography Keynote. Autoethnography: threat and promise. Brighton Journal of Research in Health Sciences, v. 1, n. 1, 2014.

GURAN, Milton. Fotografar para descobrir, fotografar para contar. Cadernos de Antropologia e Imagem, v. 10, n. 1, p. 155-165, 2000.

LAMACHIA, Claudio; GONÇALVES, Sandra K. (Org.). Direito Médico e da Saúde: o direito, a saúde e a justiça - cenários e desafios. Brasília: OAB, Conselho Federal, 2018.

MOTTA, Pedro M. R.; BARROS, Nelson F. Resenha. Cadernos de Saúde Pública, v. 31, p. 1339-1340, 2015.

MURPHY, Robert F. The body silent: the different world of the disabled. New York: Norton, 1987.

PESSOA, Marcus Fahr. Em busca da cura. Barueri: Casa da Palavra, 2013.

RAIMONDI, Gustavo. Corpos que (não) importam na prática médica: uma autoetnografia performática sobre o corpo gay na escola médica. Tese (Doutorado em Saúde Coletiva) - Faculdade de Ciências Médicas, Universidade Estadual de Campinas, 
Fabiene Gama

Campinas, 2019.

VERSIANI, Daniela G.C.B. 2005. Autoetnografias: conceitos alternativos em construção. Rio de Janeiro: 7Letras,2005.

WEBSTER, Barbara D. All of a piece: a life with multiple sclerosis. Baltimore: The Johns Hopkins University Press,1998. 